\title{
Hydrological Dynamics and Human Impact on Ecosystems of Lake Tana, Northwestern Ethiopia \\ ${ }^{1}$ Amare Sewnet Minale and ${ }^{2}$ Kameswara K.Rao \\ doi: 10.4314/ejesm.v4i1.7
}

\begin{abstract}
Lake Tana, biggest lake in Ethiopia, is very important water resource for community living and depending on the lake's resources. However, the recent development activities at the catchment areas have negatively affected the water of the lake, and the climate of the region. This study delineated how land cover modification, climate change, population increase and development activities within the catchment have influenced the hydrological dynamics of Lake Tana. The land cover modification of southern part of catchment of Lake Tana in the years 1973, 1986, 1995 and 2008 were examined using land sat images. For the last 30 years, temperature, rainfall and lake level data were evaluated to identify change in climate and lake level. The annual means of temperature, rainfall, and lake level with their decadal variation and trends were analyzed with the support of linear regression model to assess trend change. Population change for the last 25 years and development activities were also assessed. The results have revealed that within the last 35 years more than $6.2 \%$ of lake's area was converted to other land covers. Parallel to this period within the catchment there was declining of rainfall and lake level and rise in temperature. There was also increase of population and intensification of use of lake's water in recent times. Thus, it is implied that change in Lake Tana water was caused by human factors and climate changes.
\end{abstract}

Key Words: Lake Tana; Hydrological Dynamics; Climate Change; Population Increase; Land Modification; Development Activities

\section{Introduction}

Water is cyclic resource which the soil, flows through aquifers, runs along stream courses, and eventually returns to the clouds. This natural cycle is the base of all life forms and of the economy of society. Moreover, water in its basin is part of a complex ecosystem consisting of the land, plants, aquatic and other life forms and their interaction. Lakes as one part of water are one of humanity's most important resources; often viewed as highly productive biological systems. Lakes provide water for consumption, fishing, irrigation, power generation, transportation, recreation, disposal of wastes, and a variety of other domestic, agricultural, and industrial purposes. However, the increment of surface temperature could impact the hydrologic cycle and various processes of water including changes in runoff, nutrient enrichment, sediment loading, and evapotranspiration rates in a water system (Band et al. 1996; Chang et al. 2001; Evans et al. 2003).

Ethiopia is considered as water tower of Africa and endowed with a variety of aquatic ecosystems, especially a number of lakes that are of great scientific interest and economic importance. The total area of inland waters in Ethiopia is 8,800 square kilometers, representing 0.72 percent of the total surface area of the country (Greboval et al, 1994).
Lake Tana is the largest freshwater body with a surface area of $3150 \mathrm{~km} 2$, (36\% of total inland water of Ethiopia) with a maximum length of $78 \mathrm{kms}$ and width of $68 \mathrm{kms}$. The various habitats and ecosystems of the lake and associated wetlands provide a refuge for many species of flora and fauna, many of which are known to be endemic species. Due to the natural goods and services of the ecological system of the lake basin, population density is high; more than 150 persons $/ \mathrm{km} 2$. There are about 37 islands in the lake some of which with several historical monasteries and churches having religions and cultural interest (Menelik, 2004). But, caused by anthropogenic activities and underlying socio-economic factors, the integrity of the ecological systems of the Lake Tana and its adjoining wetlands are increasingly being subjected to profound impacts upon the biological, chemical and physical processes essential to maintaining the structure and functions of the ecosystems. Particularly, ever-increasing unwise utilization of resource coupled with land use and climate changes, agricultural expansion with its close proximity have become sever threats to the long term survival of the lake to function as habitats for aquatic organisms. With further increasing present negative trends, resulted from multiple interests of resource users, irreversible ecological damages and biodiversity losses are inevitable before long.

1Bahir Dar University, Department Of Geography and Environmental Studies and Phd Scholar in Department Of

Environmental Sciences, Andhra University. Sewnetamare@Yahoo.Com

2Professor, Department Of Environmental Sciences, Andhra University, India 
There is an increasing demand for irrigation and hydropower development in catchment to cope with the recurrent drought, its impacts and to increase agricultural production to cope with increasing population.

However, no more research has been conducted on this problem area in Ethiopia in general and Lake Tana basin in particular. In Ethiopia human factors, in combination with the natural conditions of climate and geology, may influence water quality to a large extent. Pollution resulting from natural and human activities, such as land use and modification and other practices associated with rapid population increase, has caused or accelerated many changes in the lakes. However, there are few studies on these problems of lakes over the last times (Elizabeth et al, 1994; Brook, 1994). Some others studied on hydrological dynamics in Ethiopia were very scarce. Those which have done studies mainly focus on spatialtemporal trend and variation of rainfall at the local level (Osman and Sauerborn, 2002; Seleshi and Zanke, 2004).

Therefore, analysis of hydrological dynamics of Lake Tana and its ecosystem was aimed at understanding of the complex interaction of these changes in their temporal and spatial patterns and to formulate focused and targeted policy interventions to sustain the life of lake to maximize its usability. Hence, lake level for the long time, land cover changes from southern parts, Lake's area from four different images, and climate and population changes and development activities as component of hydrology dynamic indicators was analyzed to assess the hydrological status of Lake Tana.

Study Area
Lake Tana is located at the Northwest of Ethiopia adjacent to Bahir Dar Town with coordinates of $11^{\circ} 36^{\prime} \mathrm{N}, 37^{\circ} 23^{\prime} \mathrm{E}$. Lake Tana, is the source of the Blue Nile, shallow, oligotrophic, and freshwater. It occupies a wide depression in the Ethiopian plateau, and was formed by volcanic blocking of the Blue Nile, probably in early Pleistocene period. Lake Tana Basin includes the high land escarpments of Gondar (Guna and Armacheho) and Gojjam (Sekela). The total area of catchment is 15,319 square kilometers, of which 3150 is the lake area (Conway, 2000). Lake Tana has a dendrite type of drainage network. It is fed nearly by 60 water sources. However, four main perennial rivers namely: Gilgel Abay, Gumara, Rib, and Megetch contribute $95 \%$ of the inflow. The shallowness of the lake gives the region or the catchment area of the lake, a" Wetland" characteristic. There are lagoons and swamps on all sides of the lake resulting from hydrological and land use changes.

The climate of Lake Tana basin is 'tropical highland monsoon'. The rainfall pattern of the year is divided into two seasons: a rainy season mainly centered on the months of June to September (kremit), and a dry season from October to April. Of the total annual rainfall, $70 \%$ to $90 \%$ occurs in the June to September, rainy season. The mean annual rainfall is about $1500 \mathrm{~mm}$. The mean annual flow at the outlet of Lake Tana is about 3.5 billion cubic meters and it varies from a maximum of 7 billion cubic meters to a minimum of 1 billion cubic meters in height and low water years respectively (LTRC, 2004). The mean maximum and minimum temperature of Lake Tana are $29.20^{c}$ and $10.90^{c}$ respectively.

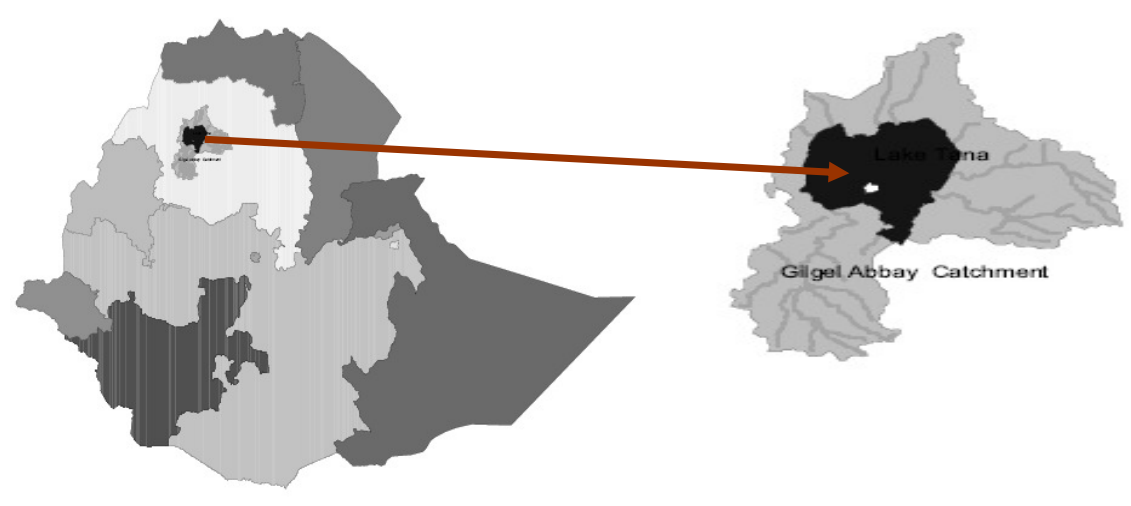

Figure 1 Location of Study Area, Ethiopia and Lake Tana Basin 



\section{Methodology}

The main data used on this study were land sat images, lake level, rainfall, temperature and population from different sources. The major data source for land cover and use analysis was http://glovis.usgs.gov where free landsat image was available. From this website 1973, 1986, 1995 and 2008 landsat images for the study area were downloaded and land cover and use dynamics of Gilgel Abbay Catchment from southern part of Lake Tana with the lake was analyzed for the last 35 years. The process of detecting land cover from the satellite images were prepared through image processing, including geometric rectification, atmospheric correction and classification of images. Supervised classification by the help of GPS points were used to produce thematic land cover maps. Only major land cover types were considered, the dispersed rural settlement for example is included in the classification of agricultural areas, because settlement in the rural areas are near their farmlands and the swamps, ponds, riparian vegetation and marsh areas were categorized under wetlands. Hence, the major land classes were: forest; agriculture and settlement area; wood and bush lands; grass and bare lands; water bodies and wetlands. After classification, calculation of the area in hectare, comparison of the land use land cover statistics within and between land class units and years was performed and the trend was determined.

The rainfall and temperature data were obtained from meteorological stations where as lake level data was obtained from Ministry of Water Resources of Ethiopia. Population data was gathered from statistical office for three population censuses of Ethiopia. The data analysis of climate change and variability include analysis of the rate of changes in decadal rainfall, temperature, and lake level. The method of moving averages, 10 years span, and the linear regression technique were used for identifying trends of long-term changes. The linear time series analysis was used to identify the nature of the phenomenon represented by the sequence of observations of the time series data. Lake level fluctuation was also calculated and graphed to see change over time on the levels of lake. Area of the Lake Tana was calculated from the four different time images to know effect of land cover change on the size of the lake. Survey data about the hydrological issues were also included with other data to substantiate the change detections. Population change in size, distribution and growth rate from catchment districts was analyzed to see the changes and its influence on lake. Four districts' population from the southern catchment was considered to assess population implication to change in Lake Tana status.

\section{Results and Discussion}

\section{a) Lake Level Analysis over time}

The lake level is the highest level at which the water has remained long enough to leave evidence on the landscape. Generally, it is the point where the natural vegetation changes from predominantly aquatic to predominantly terrestrial plants. Any land use changes within a particular watershed may cause a change in the level of a lake within the watershed. The mean annual Lake Tana level for the last 42 years (1965-2008) was almost $3 \mathrm{~m}$, and the minimum and maximum lake levels were about $2 \mathrm{~m}$ and $3.2 \mathrm{~m}$, respectively. The minimum lake level was recorded during the time water from the lake was taken for hydroelectric production in 2002.

However, there was variability of lake level which coincides with variability of rainfall in the catchment. But, the effect of precipitation on lake level was always counteracted by the rise or fall in temperature. The lake level trend was determined by the balance of precipitation and temperature because changes in precipitation affected the surface runoff inflow to the lake whereas the changes in temperature affected evaporation through the out-flux of lake water ( $\mathrm{Li}$ et al., 2007). They further pointed out that the trend of warm and dry climate might be the main reasons for the decline in lake level in the recent decades. In recent times, in Lake Tana catchment there was intense land cover modification and climate change which was manifested by rainfall decline and temperature rise, one of the causes for declining of level of Lake Tana.

Fig2 shows the long years line graph of Lake Tana level and if line graph was carefully observed, it depicts the fluctuation of the levels of Lake Tana. In sometimes of the years there were high depth records and on some other years there were low depth records. For instance in early 1970s and half of 1980s 
there were low depth records and from 19952000 there were high depth records. The lowest depth was recorded in 2002 and after that time onwards the level of Lake Tana was not able to restore to its original level and this was a good example of impact of man on lake level. Thus, the variability and recent declining of level of Lake Tana was related to changes on climate and human influence.

Decadal trend analysis of Lake Tana level was made by breaking the recorded data into four decades (1968-1977, 1978-1987, 1988-1997 and 1998-2007) to clearly observe long time changes overtime. The trend of Lake Tana level has showed variability during the decades. The mean lake level for the first decade was $2.5057 \mathrm{~m}$ and it declined to 2.4490 on the next decade as indicated in table1.The difference of lake level between two decades was about $0.0567 \mathrm{~m}$. From 1988-1997 it was about $2.6766 \mathrm{~m}$ and as compared to the previous decade it has shown increment by $0.2276 \mathrm{~m}$ and on the last decades it was declined to 2.6364 and the declining value was about $0.0402 \mathrm{~m}$. From decadal mean description there was variability of lake level and it was similar to the rainfall discussed below. Except, the second decade in all cases, the coefficient of variation showed increasing trends. This implies that there was variability of Lake Tana levels on the stated periods which have coincided with the variability of rainfall. In order to substantiate the above description, the linear logistic regression was fitted and slope was positive for the first three decades but negative for the last decade. It was $0.015, \quad 0.0041, \quad 0.0509$ and -0.1011 , respectively. Although its proportion was low, it was increasing for the first three decades and negative and declining for the last decade.

\section{b) Land cover modification on Lake Tana Catchment}

Studies on land cover changes have shown that under a modified land cover, there is a reduction in moisture recycling due to less evapotranspiration, which can contribute to a decrease in humidity in the lower atmosphere (Durieux et al., 2003; Fu and Li, 2004). The simulated warmer and drier climate with enhanced climate extremes are cumulatively impacting the soil moisture and surface runoff, and are likely to be affecting turbulent transport of water vapour and partitioning of available surface water between surface runoff and evapotranspiration.
As indicated in table 2 and fig 2 there was increase in share of $f$ arm and settlement and wood and bush lands on the stated years whereas the remaining land cover units have revealed the declining percentage. The forest, wetlands and grass lands were converted to farm and settlement lands. Unlike other land covers, Lake Tana was increasing at the beginning but started decreasing on its area share on late times. Its area coverage in 1973 from the total was $38.3 \%$ and increased to $38.4 \%$ in 1986 with increase in area by $0.1 \%$. But from this time onwards it has shown continuous declining and the decrease at the last year was very high in its share. In 1995 its coverage was $38.1 \%$ and it was declined to $35.9 \%$ at the last year with percentage decrease of $2.2 \%$. This time also coincide, with the decline of its level, and change in climate. The conversion was increasing in the late periods because of development activities taking around the lake. Thus, change in hydrological status of Lake Tana was related to modification of land cover and climate change.

\section{c) Climate change in Lake Tana Catchment}

Climate change can cause significant impacts on water resources by resulting changes in the hydrological cycle. The change in temperature and precipitation components of the cycle can have a direct consequence on the quantity of evapotranspiration component, and on the quantity of the runoff components. Consequently, the spatial and temporal water resource availability, or in general the water balance, can be significantly affected, which clearly amplifies its impact on sectors like agriculture, industry and urban development (Hailemariam, 1999).

Table 3 shows decadal mean trend of rainfall and temperature from five different stations of Lake Tana catchment. The slope (trend) of rainfall has shown declining trend of rainfall within the stated decades. In the first decade (1978-1987) it was 3.3, and has declined to -11.8 and to -12.1 within the remaining decades respectively. Similarly, the slope of temperature from the same table has indicated that the temperature from 1977-1988 was negative and low. From this decade on wards it has started to increase, from 19891998 it was 0.0343 and increased to 0.1382 . Thus, it is possible to say that rainfall within the decadal periods has shown declining rate 
while temperature was rising. This was related to decline trend of forest cover, wetland degradation and expansion of agriculture and settlement of the catchment on land cover parts. The combined effect of land cover and climate change has resulted in recent declining of Lake Tana.

\section{d) Population Increase and Development Activities in Lake Tana Catchment}

Population is one of a deriving force for environmental change. Population increase demands more land, destruct frosts in the catchment and over consume water for irrigation. The population of four districts was considered to assess impacts on Lake Tana. Table4 shows total population of catchment districts in 1984 was 580258 and in 1994 population of the same districts was 863432 and in 2007 population of districts became 1162956 (CSA, 1984; CSA, 1994; CSA, 2008). The growth of population per year from 1984 to 1994 was $4.9 \%$ and from $1994-2007$ it was $3.5 \%$. Although its growth was declining, it was increasing rapidly and brought the scarcity of land, deforestation, over use of lake's water and soil erosion in the catchment.

There are also spatial variations in population distribution within the catchment. The national population density from 2007 census was 68 persons per $\mathrm{km}^{2}$. But the crude density in the catchment was 152 persons per $\mathrm{km}^{2}$. It is one of the highest in the country. This implies that the hydrological degradation of Lake Tana in recent times was because of population increase in the catchment. Furthermore, shortage of land has forced farmers to cultivate steep slopes and shallow soils that are vulnerable to degradation and leads to influence water cycle. Thus, it is possible to say that increase in population was one of possible factors for Take Tana's hydrological declining on recent times.

Development activity for the betterment of life may damage environment including lakes, if not well managed. Human activities combined with population and other socio-economic factors have caused decline of lake's water which has resulted decrease in lake level. The need to meet high energy demand, Ethiopian government has started to develop hydroelectric power. In 1996, Chara Chara-Tis Abbay hydro-power plant was constructed by taking water from Lake Tana which has dropped level of lake in 2002. However, right after the functioning of the hydropower generation in 2002, unprecedented catastrophic impacts have exerted on the physical, ecological and economical benefits of the lake system from excess water withdrawal from the lake, accompanied with poor water management and control (Woldegabriel, G., 2006). Huge another power plan to the west of the lake was finished recently. It runs its function by drowning water from the lake. Drawing of water for hydro electric power generation was, one of possible causes for the shrinkage of Lake Tana area and declining of lake level.

The current ambitious program called "development corridor" designed to produce electric-power and to develop irrigated agriculture in Lake Tana basin, has to be seen very critically in order not to affect the whole components of the lake, and the goods and services that are provided to the nation due to the presence of the lake. The experiences from Lake Chad and Aral Sea are important example to learn, if we are learning. The expansion of agriculture with irrigation has caused decline of water within their respective localities. The loss of riparian vegetation, increase run off and soil erosion and because of showery rain their crops and animals were damaged. This implies that because of land cover changes such as deforestation, people are sensing the problem of Lake Tana hydrological degradations.

Conclusion

It is evident that human activity and catchment mismanagement have accelerated lake water degradation in recent times. It should be noted that Lake Tana water survival is related to rainfall and its managing factors. If the catchment and the tributaries of lake's water are affected it directly has impact on the lake. The use of tributaries and lake's water need management practice which enable the lake to sustain and generate long-lasting benefits for both present and future generation. 


\section{References}

Band L, Mackay D, Creed I, Semkin R, Jeffries D. (1996) Ecosystem Processes at the Watershed Scale: Sensitivity to Potential Climate Change. Limnol Oceanography 41(5):pp928-938

Brook, L. (1994) Changes in the Limn logical Behavior of a Tropical African Explosion Crater Lake: L. Hora-Kilole, Ethiopia. Limnologica 24(1)pp57-70.

Chang H, et al., (2001) Effects of Climate Change on Stream Flow and Nutrient Loading Water Resource Assoc 37(4) pp973-986

Conway, D. (2000) The Climate and Hydrology of the Upper Blue Nile River. The Geographical Journal 166: 49-62.

CSA (1984) The Population and Housing Census of Ethiopia; Results at a Country Level. Office of population and housing census commission /central statistical authority/ Addis Ababa.

(1994) The Population and Housing Census of Ethiopia; Results at a Country Level. Office of population and housing census commission /central statistical Authority/ Addis Ababa.

(2008) Summary Statistical Draft Report of National Population Statistics. Addis Ababa, Ethiopia.

Durieux, L., Machado, L., Laurent, H. (2003) The Impact of Deforestation on Cloud Cover Over The Amazon Area of Deforestation. Remote Sens. Environ. 86, pp132-140.

Elizabeth, K., Getachew, T., Taylor, W.D., and Zinabu, G.M. (1994) Eutrophication of Lake Hayq in the Ethiopian highlands. J. Plankton Res. 14 pp1473-1482.
Evans B, et al., (2003) A Comprehensive GISBased Modeling Approach for Predicting Nutrient Loads in Watersheds. Journal of Spatial Hydrology 2(2):pp1-18

Greboval, D., Bellemans, M., and Fryd, M. (1994) Fisheries Characteristics of the Hared Lakes of the East African Rift. CIFA Technical Paper No. 24. Rome: FAO.

Hailemariam, K. (1999) Impact of Climate Change on the Water Resources of Awash River Basin, Ethiopia, Climate Res., 12, pp91-96,.

LTRC (2004) Resource Management in the Lake Tana Basin: Research Link Project Proposal. Bahir Dar University.

$\mathrm{Fu}, \mathrm{R}$. , and W. Li (2004) the Influence of the Land Surface on the Transition from Dries to Wet Season in Amazonia. Theory. Appl. Climatol., 78,pp 97-110.

Menilik Molla (2004) Study on Environmental Impacts Assessment of Lake Tana,ANRS, EPLAUA, Bahir Dar, Ethiopia

Osman and Sauerborn (2002) A Preliminary Assessments of Characteristics and LongTerm Variability of Rainfall in Ethiopia -Basis for Sustainable Land use and Resource Management

Seleshi, Y. and Zanke, U. (2004) Recent Changes in Rainfall and Rainy Days in Ethiopia, International Journal of Climatology, 24 pp 973-983.

Woldegabriel G/kidan (2006) Current Water Utilization Level of Lake Tana and Future Trends: The Case For Conflicting Interest:Lake Tana And Its Environs: Conservation, Utilization, Development and Threats, Bahir Dar.

Table1 decadal trend analysis of Lake Tana level

\begin{tabular}{|l|l|l|l|l|}
\hline Parameters & \multicolumn{4}{l|}{ Decadal periods } \\
\hline & $\mathbf{1 9 6 8 - 1 9 7 7}$ & $\mathbf{1 9 7 8 - 1 9 8 7}$ & $\mathbf{1 9 8 8 - 1 9 9 7}$ & $\mathbf{1 9 9 8 - 2 0 0 7}$ \\
\hline Mean & 2.5057 & 2.4490 & 2.6766 & 2.6364 \\
\hline CV\% & 5.64 & 4.95 & 7.74 & 16.54 \\
\hline Max & 2.6589 & 2.6138 & 3.0798 & $3.1968(2000)$ \\
\hline Min & 2.2762 & 2.2366 & 2.3918 & $1.9775(2003)$ \\
\hline Slope & 0.015 & 0.0041 & 0.0509 & -0.1011 \\
\hline
\end{tabular}


Table2 land cover in Lake Tana and its southern catchment from 1973 to 2008

\begin{tabular}{|c|c|c|c|c|c|c|c|c|}
\hline Land cover & 1973 & & 1986 & & 1995 & & 2008 & \\
\hline & $\begin{array}{l}\text { Area in } \\
\text { ha* }\end{array}$ & $\%$ & $\begin{array}{l}\text { Area in } \\
\text { ha }\end{array}$ & $\%$ & $\begin{array}{l}\text { Area in } \\
\text { ha }\end{array}$ & $\%$ & $\begin{array}{l}\text { Area in } \\
\text { ha }\end{array}$ & $\%$ \\
\hline Forest & 9328 & 1.2 & 4527 & 0.6 & 3298 & 0.4 & 2581 & 0.3 \\
\hline $\begin{array}{l}\text { Wood and bush } \\
\text { land }\end{array}$ & 24645 & 3.1 & 39980 & 5.1 & 60148 & 7.6 & 60863 & 7.7 \\
\hline $\begin{array}{l}\text { Grass and bare } \\
\text { land }\end{array}$ & 162481 & 20.6 & 109550 & 13.9 & 91748 & 11.6 & 73026 & 9.3 \\
\hline $\begin{array}{l}\text { Farm and } \\
\text { settlement land }\end{array}$ & 205993 & 26.1 & 274947 & 34.9 & 286261 & 36.3 & 324536 & 41.2 \\
\hline Lake Tana & 301899 & 38.3 & 302946 & 38.4 & 301082 & 38.1 & 282990 & 35.9 \\
\hline Wetlands & 84069 & 10.7 & 56465 & 7.2 & 45878 & 5.8 & 44419 & 5.6 \\
\hline Total & 788415 & 100 & 788415 & 100 & 788415 & 100 & 788415 & 100 \\
\hline
\end{tabular}

*all areas of land classes are in hectare

Table3 Decadal climate trends in Southern part of Lake Tana catchment

\begin{tabular}{|c|c|c|c|}
\hline & 1978-1987 & 1988-1997 & 1998-2007 \\
\hline $\begin{array}{l}\text { Slope of mean } \\
\text { Temp. }\end{array}$ & -0.1178 & 0.0343 & 0.1382 \\
\hline $\begin{array}{l}\text { Slope of mean } \\
\text { rainfall }\end{array}$ & 3.2557 & -11.769 & -12.143 \\
\hline
\end{tabular}

Table4.size and spatial distribution of population of districts in Lake Tana catchment

\begin{tabular}{|l|l|l|l|l|}
\hline \multirow{2}{*}{} & \multicolumn{4}{|c|}{ Census years } \\
\cline { 2 - 5 } & & 1984 & 1994 & 2007 \\
\hline \multirow{2}{*}{ sopulation } & Both Sexes & 580258 & 863432 & 1162956 \\
& Male & 296227 & 436250 & 585399 \\
& Female & 284031 & 427182 & 577557 \\
\hline \multicolumn{2}{|l|}{ Parts of Catchment } & Population & Area in km2 & Population \\
& size & & 130 \\
\hline Upper catchment & 138652 & 1067.45 & 164 \\
\hline Middle catchment & 448113 & 2730.52 & 148 \\
\hline Lower catchment & 355887 & 2403.55 & 152 \\
\hline \multicolumn{2}{|l|}{ Total } & $942652 *$ & 6201.52 & \\
\hline
\end{tabular}

*Population of Bahir Dar Town was not included

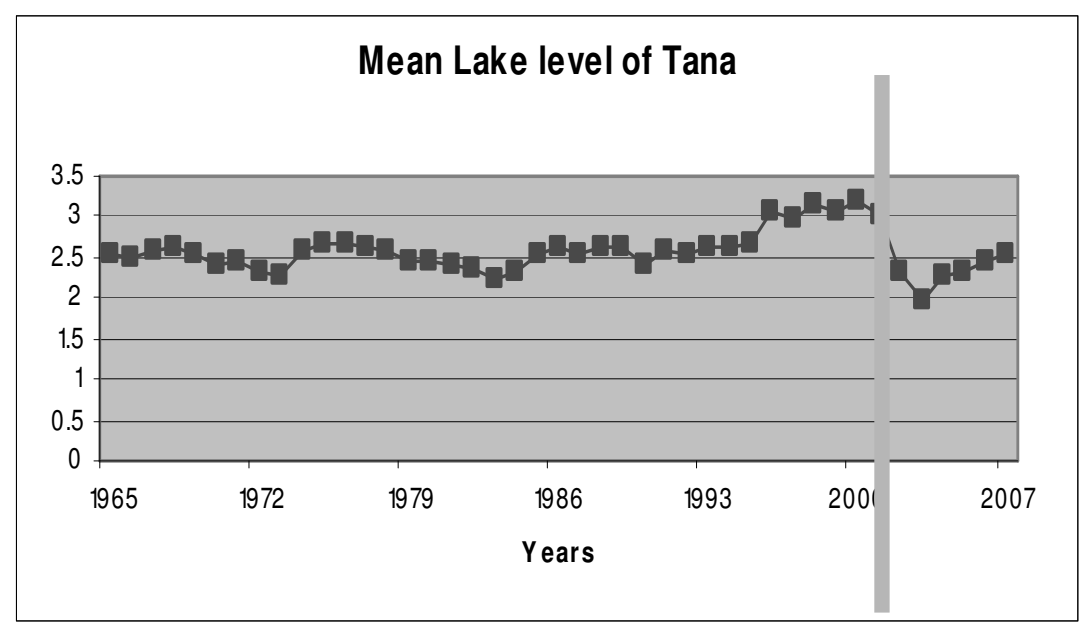

Fig 2 average lake level of Lake Tana from1965 to 2007 

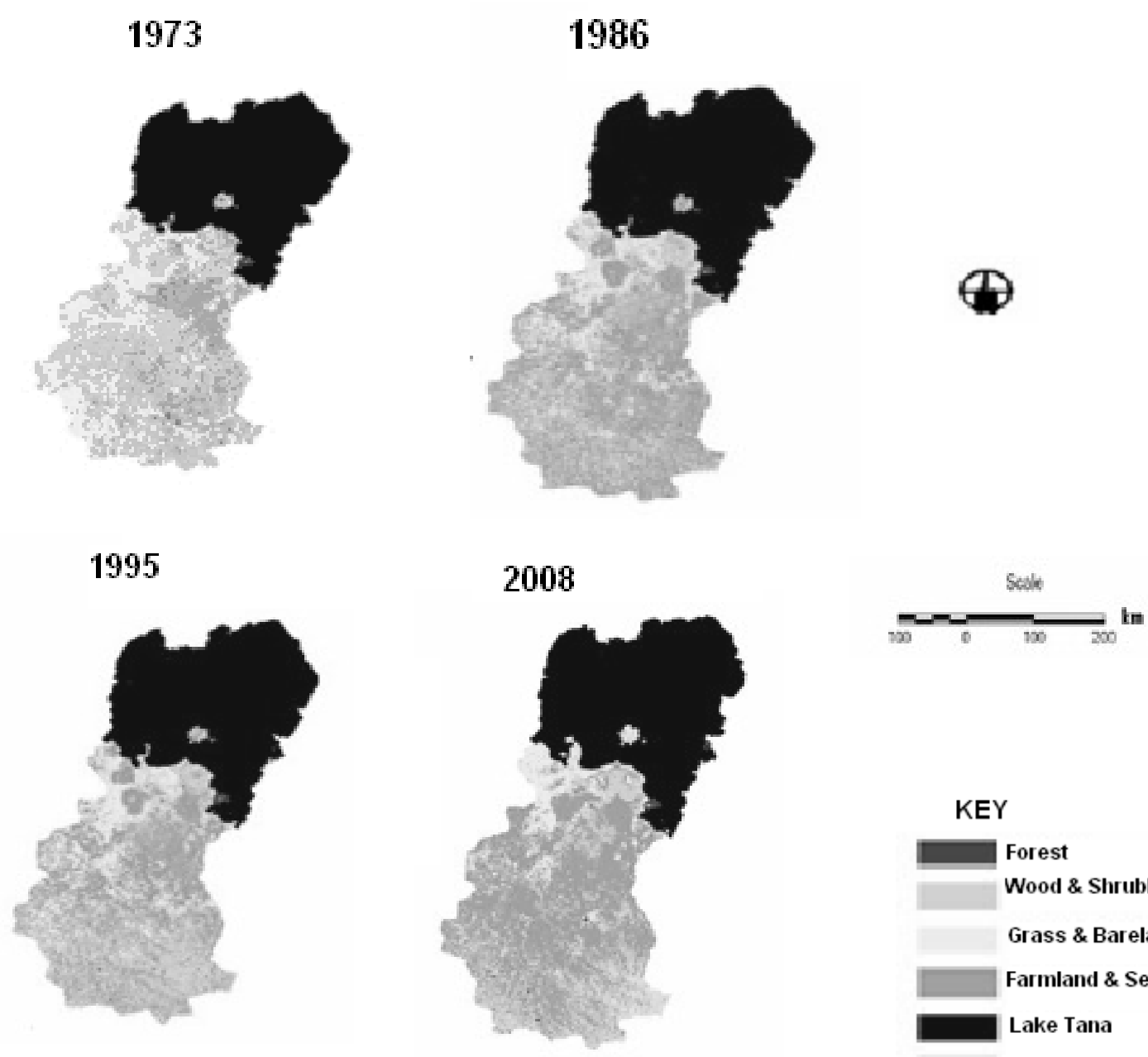

Fig3 land cover maps of Lake Tana and its southern catchment from 1973-2008 